\title{
Medication-related osteonecrosis of the jaw. Introduction of a new modified experimental model ${ }^{1}$
}

\author{
Cláudia Curra ${ }^{\mathrm{I}}$, Camila Lopes Cardoso ${ }^{\mathrm{II}}$, Osny Ferreira Júnior ${ }^{\mathrm{III}}$, Marcos Martins Curi ${ }^{\mathrm{IV}}$, Mariza Akemi Matsumoto ${ }^{\mathrm{V}}$, Bruno \\ Cavalini Cavenago ${ }^{\mathrm{VI}}$, Pâmela Letícia dos Santos ${ }^{\mathrm{IV}}$, Joel Ferreira Santiago Júnior ${ }^{\mathrm{VII}}$
}

DOI: http://dx.doi.org/10.1590/S0102-865020160050000003

IDDS, MSc student, Department of Oral Surgery, Universidade Sagrado Coração (USC), Bauru-SP, Brazil. Design of the study, technical procedures, MicroCt evaluation, manuscript writing.

IIDDS, MSc, PhD, Assistant Professor, Department of Oral Surgery, USC, and Postdoc-student, Department of Oral Surgery, Bauru Dental School, Universidade de São Paulo (USP), Bauru-SP, Brazil. Design of the study, technical procedures, interpretation of data, MicroCt evaluation, microscopic evaluation, manuscript writing.

IIIDDS, MSc, PhD, Assistant Professor, Department of Oral Surgery, Bauru Dental School, USP, Bauru-SP, Brazil. Design of the study, interpretation of data, manuscript writing.

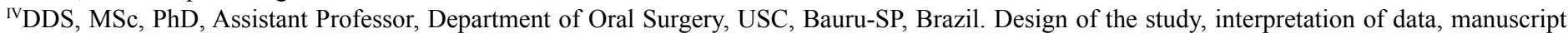
writing.

${ }^{\vee}$ DDS, MSc, PhD, Assistant Professor, Universidade Estadual Paulista (UNESP), Araçatuba-SP, Brazil. Design of the study, interpretation of data, microscopic evaluation, manuscript writing.

${ }^{\mathrm{V}}$ DDS, MSc, PhD, Postdoc-student, Department of Endodontics, Bauru Dental School, USP, Bauru-SP, Brazil. Interpretation of data, MicroCt evaluation, manuscript writing.

${ }^{\mathrm{VII} D D S}$, MSc, PhD, Assistant Professor, Department of Implantology, Bauru Dental School, USP, Bauru-SP, Brazil. Interpretation of data, statistical analysis, manuscript writing.

\section{ABSTRACT}

PURPOSE: To evaluate a modified experimental model for medication-related osteonecrosis of the jaw (MRONJ) through the upper right central incisor extraction followed by intravenous bisphosphonate administration.

METHODS: Forty five rats underwent the upper right central incisor tooth extraction were divided in 2 groups: Group I - experimental group, 30 rats received an intravenous administration protocol of zoledronic acid $35 \mu \mathrm{g} / \mathrm{kg}$ into the tail vein every two weeks, totalizing four administrations, during eight weeks of administration, previously the extraction, and Group II - control group, 15 rats didn't received any medication before extraction. The groups were subdivided in postoperative periods: 14/28/42 days. Clinical analysis and microtomography were performed to verify the presence of osteonecrosis. In addition, descritive histological analysis of hematoxylineosin stained sections was performed to evaluate the presence of osteonecrosis or necrotic foci.

RESULTS: Twelve (40\%) rats, from experimental group, showed clinical signs of MRONJ ( $p=0.005$ ), however, all samples showed imaginologic findings like osteolysis and loss of integrity of the cellular walls $(\mathrm{p} \leq 0.001)$. Microscopic evaluation revealed osteonecrosis areas with microbial colonies and inflammatory infiltrate $(\mathrm{p} \leq 0.001)$. In the control group, all animals presented the chronology of a normal wound healing.

CONCLUSIONS: The presence of medication-related osteonecrosis of the jaw after maxillary central incisor extraction in rats. This new experimental model may be considered an option for the study of MRONJ.

Key words: Bisphosphonate-Associated Osteonecrosis of the Jaw. Rats. 


\section{Introduction}

The bisphosphonates (BP) belong to a group of drugs commonly administered to treat benign bone disorders such as osteoporosis, osteogenesis imperfecta and Paget's disease as well as solid malignant neoplasms involving bones, such as multiple myeloma ${ }^{2}$. The main effect of the drug is inhibition of bone resorption $^{1-5}$. Despite the great benefits of BP in patients with benign or malignant conditions, an oral complication was observed arising from the use of this drug, especifically: Medication-related osteonecrosis of the jaw (MRONJ), which aroused attention from the medical and dental professionals.

The clinical features of MRONJ may vary according to the patient clinical condition, their medical and dental background, drug administration time and method, but it is usually characterized by an exposure of jaw bone surrounded by oral mucosa with inflammatory signs and pain symptoms ${ }^{6-8}$. MRONJ incidence has been estimated to be 1:143,000 patients/year who underwent dental procedures ${ }^{2,9}$ with an estimate of $0.8-12 \%$ in patients receiving intravenous administration for controlling malignant neoplasms ${ }^{10}$ and $0.00038-0.06 \%$ in patients treated with oral $\mathrm{BP}^{11}$. MRONJ etiopathogenesis has been widely investigated and it is not yet fully defined. Currently, the interaction between bone metabolism, infection, local trauma and theories of bone remodeling suppression, antigenic effect and oral mucosa toxicity have been studied to elucidate its etiopathogenesis ${ }^{2,12-14}$.

In this way, in vivo study using animal models are of great value due to possibility of a more accurate biological investigation. In literature, several animals have been used to define a methodology that can mimic MRONJ in humans ${ }^{15}$, but rats are the most used and molar teeth extraction is the predominant procedure performed to induce MRONJ. However, this procedure presents some difficulties, regarding the access and mainly because of roots' teeth anatomy, which are frequently fractured during the procedure, increasing the number of animals ${ }^{16}$. The purpose of this study was to present a modified experimental model for MRONJ using the maxillary central incisor extraction in rats under the intravenous zoledronic acid administration. The authors have formulated the hypothesis that this modified experimental model may be useful in the study of MRONJ taking into consideration the easy accessibility of this technique and the favorable central incisor tooth anatomy.

\section{Methods}

Institutional Committee for Animal Care and Use approved the experimental protocol (Protocol CEUA/USC 12/14) according to the Council for International Organization of Medical Sciences (CIOMS) ethical code for animal experimentation.

Forty-five male rats (Rattus norvegicus, albinus, Wistar), weighting about $250 \mathrm{~g}$ were used in this study, and underwent the upper right central incisor tooth extraction were divided in two groups: Group I - experimental group, 30 rats received an intravenous administration protocol of zoledronic acid $35 \mu \mathrm{g} /$ $\mathrm{kg}$ (Zometa, Novartis, Basel, Switzerland, $35 \mu \mathrm{g} / \mathrm{kg}$ ) into the tail vein every two weeks, according to Hokugo et al. ${ }^{17}$. A total of four administrations were carried out making up eight weeks of administration, previously the extraction, and Group II - control group, 15 rats didn't received any medication before extraction.

The extraction procedure was performed in all animals nine weeks subsequent to the beginning of the systemic treatment ${ }^{17}$, by the same operator, which was calibrated prior to the procedure, followed by the methodology previously described ${ }^{18,19}$. For surgical interventions, the animals were initially sedated with an intramuscular injection, the base xylazine chloride at a dose of $15 \mathrm{mg} / \mathrm{kg}$, and anesthetized with a combination of ketamine chloride $(25 \mathrm{mg} / \mathrm{kg})$ and xylazine $(15 \mathrm{mg} / \mathrm{kg})$ intramuscularly. After asepsis, the maxillary right central incisor was extracted ${ }^{18,19}$. A properly sharpened spatula was used to detach soft tissue and tooth dislocation and previously worn out tweezers to get and extract the tooth. Dipyrone $1 \mathrm{mg} / \mathrm{kg} /$ day was administered intramuscularly as a single dose in postoperative procedure for analgesia control. The animals were euthanized by the use of thiopental injection of $150 \mathrm{mg} / \mathrm{kg}$ with $10 \mathrm{mg}$ of lidocaine via peritoneal route, after 14 , 28, 42 days of observation. The animals were clinically observed and the following was recorded: the presence of exposed bone on the area, the presence of suppuration and bone sequestrum.

A computed microtomography (MicroCT, Skyscan, Belgium, 55Kvp; 72mA, high resolution) exam was carried out to assess the integrity of the alveolar walls and the presence of osteolysis. Samples were fixed in $10 \%$ buffered formalin for 7 days, decalcified in $4.7 \%$ EDTA pH 7.0 for 35 days, histologically processed, and embedded in paraffin wax. All samples were embedded to provide longitudinal cuts. Semi-serial longitudinal sections of $5 \mu \mathrm{m}$ each were obtained and stained by hematoxylineosin for evaluation by light microscopy. Qualitative histological evaluation was performed on a blinded fashion (light microscopy, 40 magnification) in all samples in order to evaluate the presence of osteonecrosis o necrotic foci, as previously described by BarbaRecreo $^{16}$. 


\section{Statistical analysis}

Data from measurements were organized in Excel table (Microsoft Office Excel, Redmond, WA, USA). The data were submitted to the software SigmaPlot (SigmaPlot, San Jose, CA, EUA), version 12.3 and analyzed for normal distribution (ShapiroWilk test) and subsequently it was adopted Mann-Whitney Rank Sum Test (Factors: Experimental and Control Group). The level of significance adopted was $5 \%$.

\section{Results}

In the experimental group (I), clinical features observed after 14 days subsequent to the extraction were: 12 out of 30 animals (40\%) showed bone exposure compatible with MRONJ, p=0.005 (Figures 1 and 2, Table 1).

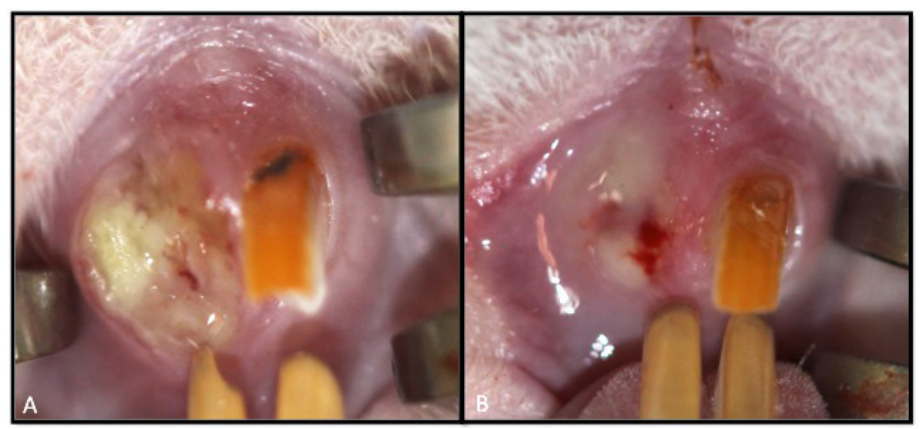

FIGURE 1 - Clinical features of MRONJ. Non vital exposed bone (A) and suppuration in the alveolar region $(\mathbf{B})$.

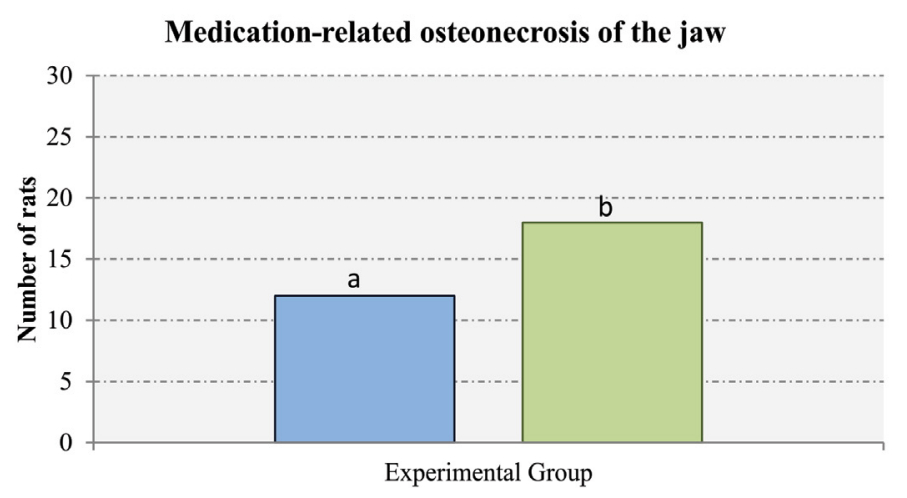

$\square$ MRONJ detected clinically $\square$ MRONJ Not detected clinically

FIGURE 2 - Comparison of the presence of clinical bone exposure between groups.
TABLE 1 - Results of all analyses in each group.

\begin{tabular}{ccccc}
\hline GROUPS & $\begin{array}{c}\text { MRONJ } \\
\text { detected } \\
\text { clinically }\end{array}$ & $\begin{array}{c}\text { Presence } \\
\text { of mucosal } \\
\text { integrity }\end{array}$ & $\begin{array}{c}\text { Imaginologic } \\
\text { findings of } \\
\text { MRONJ }\end{array}$ & $\begin{array}{c}\text { Micros- } \\
\text { copic } \\
\text { findings of } \\
\text { MRONJ }\end{array}$ \\
\hline $\begin{array}{c}\text { I - Expe- } \\
\text { rimental } \\
(\mathrm{n}=30)\end{array}$ & $40 \%^{\mathrm{a}}$ & $60 \%^{\mathrm{a}}$ & $100 \%^{\mathrm{a}}$ & $100 \%^{\mathrm{a}}$ \\
$\begin{array}{c}\mathrm{II}- \\
\text { Control } \\
(\mathrm{n}=15)\end{array}$ & $0 \% \mathrm{o}^{\mathrm{b}}$ & $100 \% \mathrm{~b}$ & $0 \% \mathrm{o}^{\mathrm{b}}$ & $0 \% \mathrm{o}^{\mathrm{b}}$ \\
\hline
\end{tabular}

*Mann-Whitney test: $a, b=p<0.05$

Computed microtomography identified osteolysis and loss of integrity of the alveolar walls in all samples $(100 \%)$, $\mathrm{p} \leq 0.001$ (Figure 3, Table 1).

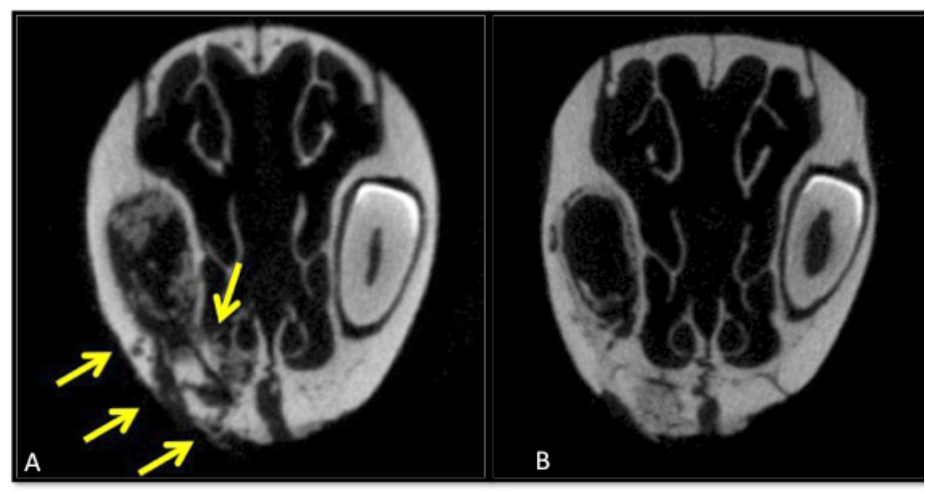

FIGURE 3 - Figures from computed microtomography showing osteolysis and loss of integrity of the alveolar walls in the cervical region of tooth socket (right side, see yellow arrow) (A). Other sample showing some imaginologic findings in the middle of socket $(\mathbf{B})$.

Microscopic examination showed osteonecrosis areas with microbial colonies and inflammatory infiltrate in all samples (100\%), $\mathrm{p} \leq 0.001$ (Figure 4, Table 1). In the control group (II), all animals $(n=15)$ presented the chronology of a normal wound healing.

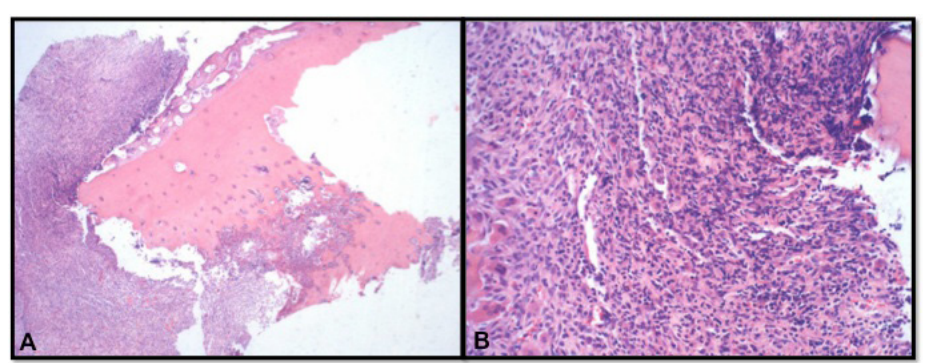

FIGURE 4 - Photomicrographs showing osteonecrosis. Inflammatory infiltrate surrounding non vital bone (A. Hematoxylin-eosin stain, $\mathrm{x} 40$ ); Detail of region (B. Hematoxylin-eosin stain, x100). 


\section{Discussion}

The American Association of Oral and Maxillofacial Surgeons (AAOMS) revised edition statements on bisphosphonaterelated ONJ (BRONJ), the diagnosis BRONJ was changed to medication-related ONJ (MRONJ), which reflects a consideration of the fact that $\mathrm{ONJ}$ also occurs for denosumab, a bone resorption inhibitor of the receptor activator of nuclear factor-kappa B ligand (RANKL) antibody family, and bevacizumab, an antiangiogenesis inhibitor ${ }^{20}$. MRONJ has been exhaustively studied in order to reveal new information on various aspects including its etiopathogenesis and treatment. Animal models are still considered essential in making these aspects clear, given the limitation of research in humans. The only limitation described is with respect to the lack of pain, a symptom which is not accurately measured in animals ${ }^{15}$.

The administration of bisphosphonates in rats required for MRONJ induction are in less quantity when compared to humans, allowing the reproduction of the experiment in the short term $^{15}$. In this study, the administration of bisphosphonates was based on the methodology previously described by Hokugo in $2010^{17}$ which simulated MRONJ induction and established an animal model which is able to be compared to humans ${ }^{17}$. Here in, it was found $40 \%$ of MRONJ clinical finding, that is, lack of oral mucosa recover and bone exposure. We consider a considerable value comparing with humans. This study evaluated the effects of intravenous bisphosphonate administration following the maxillary central incisor extraction (instead of molars) in this new modified experimental model in rats which has not been reported in the literature. Although the anatomy of the upper central incisor in Wistar rats can also be considered a challenge for a novice researcher, when performed correctly, it allows the study of wound healing and adjacent bone ridges involved in the MRONJ, without the presence of root remnants, a fairly common condition after upper molars extraction in rats. Besides the fact that this group of teeth (maxillary central incisor) being an alveolar repairing study model for over decades ${ }^{18,19}$, we could observed two facts, an easy accessibility for the tooth extraction procedure and a facility to identify / diagnose clinical signs of MRONJ. In this context, it is noteworthy that when the technique is not well carried out, tooth fracture often occurs because their anatomy is quite curved and, if the root apical portion with germinal tissue remains inside the socket, the tooth grows continuously.

Recent literature review reported the incidence of MRONJ in oncologic patients prescribed intravenous BP ranges of $0-12$ per 100,000 patients/year and the prevalence is $0 \%$ to $0.186 \%{ }^{2}$. This study found $40 \%$ of MRONJ clinical finding, that is, lack of oral mucosa recover and bone exposure. Considering the current discussion of MRONJ clinical stage classification a very interesting fact was observed in this study ${ }^{21,22}$.

In a literature review of experimental models on $\mathrm{MRONJ}^{15}$, authors considered 10 small animal model $\mathrm{s}^{23-32}$, and 5 large animal models ${ }^{15,33-37}$. In all studies, when used as the extraction inducing factor, premolars and molars were used ${ }^{23-32}$. From 10 studies with rodents, which were used different induction protocols, only 5 revealed MRONJ lesions clinically detected ${ }^{24,26,28,29,32}$, however, in 9 studies, osteonecrosis was detected microscopically ${ }^{23-30,32}$. Only one study did not reveal this information ${ }^{31}$. When we compare the other published models with the present study, we note that the correlation between clinical and microscopic analysis are similar, since $100 \%$ of cases found osteonecrosis microscopically and not all cases are detected clinically.

After more than a decade of knowledge concerning this clinical entity, there are several reports about MRONJ, however there is an unusual feature compared to the one previously reported: the absence of exposed bone in the mouth. This clinical variant, still rare, generally exhibits some signs or prominent symptom on jaw bones, but they are only confirmed by imaging studies. As consequence of some reports about this clinical variant, the presence of exposed necrotic bone in the mouth became just one more clinical manifestation of MRONJ, changing its main diagnosis criterium ${ }^{21,22,38-40}$. Although most of the dental sockets (18 out of 30 ) were covered by mucosa in the experimental group, MicroCT images revealed bone erosion and pathological fractures in a $100 \%$ of the animals, compatible with MRONJ, which can include diffuse osteolysis and bone sequestrum, even with no bone exposure. This is the presence of important imaging finds, such as osteolysis, and loss of alveolar integrity in all specimens. This clinical variant generally exhibits some signs or prominent symptom on jaw bones, but they are only confirmed by imaging studies. These imaging aspects present a wide range of manifestations, from increased density of the hard core, diffuse osteolysis, increased radiopacity of the area involved to sequestrum formation and even pathological fracture of the affected region, but no association with bone exposure in the mouth ${ }^{40}$. In view of this clinical situation, some authors have reported MRONJ experience without bone exposure to the oral environment, and found difficult to classify such entity in relation to the classification proposed by Ruggiero ${ }^{21,22}$. From these initial reports, other authors have also reported new cases of MRONJ without bone exposure, suggesting a review of the classification previously established, since these cases would be erroneously classified as stage " 0 ", but with imaging alterations and symptoms 
of MRONJ stages " 1 ", "2" and " 3 "22. Taking in consideration in this context, the present study demonstrated important bone alterations revealed by microtomography. Knowledge of the imaging aspects of MRONJ is still little discussed in the literature, and it is of valuable importance, as some cases of osteonecrosis may be asymptomatic, even absent of clinical bone exposure, being imaging the only diagnostic tool in these cases. As well as other bone diseases, MRONJ must have well defined aspects to get the final diagnosis and, also, in pointing out early alterations and the possibility to establish a prevention plan ${ }^{41,42}$.

\section{Conclusions}

The maxillary central incisor extraction of rats under IV administration of zoledronic acid induced the onset of medicationrelated osteonecrosis of the jaw in $40 \%$ of the animals. This modified experimental model may be considered a new and alternative model for the study of MRONJ.

\section{References}

1. Russell RG: Bisphosphonates: the first 40 years. Bone. 2011;49:219. PMID: 21555003.

2. Khan AA, Morrison A, Hanley DA, Felsenberg D, McCauley LK, O'Ryan F, Reid IR, Ruggiero SL, Taguchi A, Tetradis S, Watts NB, Brandi ML, Peters E, Guise T, Eastell R, Cheung AM, Morin SN, Masri B, Cooper C, Morgan SL, Obermayer-Pietsch B, Langdahl BL, Al Dabagh R, Davison KS, Kendler DL, Sándor GK, Josse RG, Bhandari M, El Rabbany M, Pierroz DD, Sulimani R, Saunders DP, Brown JP, Compston J; International Task Force on Osteonecrosis of the Jaw. Diagnosis and management of osteonecrosis of the jaw: a systematic review and international consensus. J Bone Miner Res. 2015;30:3-23. PMID: 25414052.

3. Drake MT, Clarke BL, Khosla S. Bisphosphonates: mechanism of action and role in clinical practice. Mayo Clin Proc. 2008;83:103245. PMID: 18775204.

4. Dominguez LJ, Di Bella G, Belvedere M, Barbagallo M: Physiology of the aging bone and mechanisms of action of bisphosphonates. Biogerontology. 2011;12:397-08. PMID: 21695491.

5. Russell RG, Xia Z, Dunford JE, Oppermann U, Kwaasi A, Hulley PA, Kavanagh KL, Triffitt JT, Lundy MW, Phipps RJ, Barnett BL, Coxon FP, Rogers MJ, Watts NB, Ebetino FH. Bisphosphonates: an update on mechanisms of action and how these relate to clinical efficacy. Ann N Y Acad Sci. 2007;1117:209-57. PMID: 18056045.

6. Advisory Task Force on Bisphosphonate-Related Ostenonecrosis of the Jaws, American Association of Oral and Maxillofacial Surgeons. American Association of Oral and Maxillofacial Surgeons position paper on bisphosphonate-related osteonecrosis of the jaws. J Oral Maxillofac Surg. 2007;65:369-76. PMID: 17307580.

7. Ruggiero SL, Fantasia J, Carlson E. Bisphosphonate-related osteonecrosis of the jaw: background and guidelines for diagnosis, staging and management. Oral Surg Oral Med Oral Pathol Oral Radiol Endod. 2006;102:433-41. PMID: 16997108.

8. Ruggiero SL. Bisphosphonate-related osteonecrosis of the jaw: an overview. Ann N Y Acad Sci. 2011;1218:38-46. PMID: 20946580.
9. Migliorati CA, Casiglia J, Epstein J, Jacobsen PL, Siegel MA, Woo SB. Managing the care of patients with bisphosphonate-associated osteonecrosis: an American Academy of Oral Medicine position paper. J Am Dent Assoc. 2005;136:1658-68. PMID: 16383047.

10. Ruggiero SL, Dodson TB, Assael LA, Landesberg R, Marx RE, Mehrotra B; American Association of Oral and Maxillofacial Surgeons. American Association of Oral and Maxillofacial Surgeons position paper on bisphosphonate-related osteonecrosis of the jaws--2009 update. J Oral Maxillofac Surg. 2009;67:2-12. PMID: 19371809.

11. Mavrokokki T, Cheng A, Stein B, Goss A. Nature and frequency of bisphosphonate-associated osteonecrosis of the jaws in Australia. J Oral Maxillofac Surg. 2007;65:415-23. PMID:17307586.

12. Allen MR, Burr DB. The pathogenesis of bisphosphonate-related osteonecrosis of the jaw: so many hypotheses, so few data. J Oral Maxillofac Surg. 2009;67:61-70. PMID: 19371816.

13. Marx RE, Sawatari Y, Fortin M, Broumand V. Bisphosphonateinduced exposed bone (osteonecrosis/osteopetrosis) of the jaws: risk factors, recognition, prevention, and treatment. J Oral Maxillofac Surg. 2005;63:1567-75. PMID: 16243172.

14. Reid IR, Bolland MJ, Grey AB. Is bisphosphonate-associated osteonecrosis of the jaw caused by soft tissue toxicity? Bone. 2007;41:318-20. PMID: 17572168.

15. Sharma D, Hamlet S, Petcu E, Ivanovski S. Animal models for bisphosphonate-related osteonecrosis of the jaws-an appraisal. Oral Dis. 2013;19:747-54. PMID: 23346935.

16. Barba-Recreo P, Del Castillo Pardo de Vera JL, García-Arranz M, Yébenes L, Burgueño M. Zoledronic acid - related osteonecrosis of the jaws. Experimental model with dental extractions in rats. J Craniomaxillofac Surg. 2014;42:744-50. PMID: 24342733.

17. Hokugo A, Christensen R, Chung EM, Sung EC, Felsenfeld AL, Sayre JW, Garrett N, Adams JS, Nishimura I. Increased prevalence of bisphosphonate-related osteonecrosis of the jaw with vitamin D deficiency in rats. J Bone Miner Res. 2010;25:1337-49. PMID: 20200938.

18. Rodrigues MT, Cardoso CL, Carvalho PS, CestariTM, Feres M, Garlet GP, Ferreira O Jr. Experimental alveolitis in rats: microbiological, acute phase response and histometric characterization of delayed alveolar healing. J Appl Oral Sci. 2011;19:260-8. PMID: 21625744.

19. Cardoso CL, Ferreira Júnior O, Carvalho PS, Dionísio TJ, Cestari TM, Garlet GP. Experimental dry socket: microscopic and molecular evaluation of two treatment modalities. Acta Cir Bras. 2011;26:36572. PMID: 21952659.

20. Ruggiero SL, Dodson TB, Fantasia J, Goodday R, Aghaloo T, Mehrotra B, O'Rya F. American Association of Oral and Maxillofacial Surgeons. American Association of Oral and Maxillofacial Surgeons position paper on medication-related osteonecrosis of the jaw - 2014 update. J Oral Maxillofac Surg. 2014;72:1938-56. PMID: 25234529.

21. Ruggiero SL, Fantasia J, Carlson E. Bisphosphonate-related osteonecrosis of the jaw: background and guidelines for diagnosis, staging and management. Oral Surg Oral Med Oral Pathol Oral Radiol Endod. 2006;102:433-41. PMID: 16997108.

22. Junquera L, Gallego L. Nonexposed bisphosphonate-related osteonecrosis of the jaws: another clinical variant? J Oral Maxillofac Surg. 2008;66:1516-7. PMID: 18571043.

23. Gotcher JE, Jee WS. The progress of the periodontal syndrome in the rice cat II. The effects of a diphosphonate on the periodontium. J Periodontal Res. 1981;16:441-55. PMID: 6459441.

24. Sonis ST, Watkins BA, Lyng GD, Lerman MA, Anderson KC. Bony changes in the jaws of rats treated with zoledronic acid and dexamethasone before dental extractions mimic bisphosphonate- 
related osteonecrosis in cancer patients. Oral Oncol. 2009;45:16472. PMID: 18715819.

25. Senel FC, Kadioglu Duman M, Muci E, Cankaya M, Pampu AA, Ersoz S, Gunhan O. Jaw bone changes in rats after treatment with zoledronate and pamidronate. Oral Surg Oral Med Oral Pathol Oral Radiol Endod. 2010;109:385-91. PMID: 20060339.

26. Marino KL, Zakhary I, Abdelsayed RA, Carter JA, O’Neill JC, Khashaba RM, Elsalanty M, Stevens MR, Borke JL. Development of a rat model of bisphosphonate-related osteonecrosis of the jaw (BRONJ). J Oral Implantol. 2012;38: 511-8. PMID: 21905888.

27. Aghaloo TL, Kang B, Sung EC, Shoff M, Ronconi M, Gotcher JE, Bezouglaia O, Dry SM, Tetradis S. Periodontal disease and bisphosphonates induce osteonecrosis of the jaws in the rat. J Bone Miner Res. 2011;26:1871-82. PMID: 21351151.

28. Abtahi J, Agholme F, Sandberg O, Aspenberg P. Bisphosphonateinduced osteonecrosis of the jaw in a rat model arises first after the bone has become exposed. No primary necrosis in unexposed bone. J Oral Pathol Med. 2012;41:494-9. PMID: 22268631.

29. Biasotto M, Chiandussi S, Zacchigna S, Moimas S, Dore F, Pozzato G, Cavalli F, Zanconati F, Contardo L, Giacca M, Di Lenarda R. A novel animal model to study non-spontaneous bisphosphonates osteonecrosis of jaw. J Oral Pathol Med. 2010;39:390-6. PMID: 20202091.

30. Ali-Erdem M, Burak-Cankaya A, Cemil-Isler S, Demircan S, Soluk M, Kasapoglu C, Korhan-Oral C. Extraction socket healing in rats treated with bisphosphonate: animal model for bisphosphonate related osteonecrosis of jaws in multiple myeloma patients. Med Oral Patol Oral Cir Bucal. 2012;16:e879-83. PMID: 21743422.

31. Kobayashi Y, Hiraga T, Ueda A, Wang L, Matsumoto-Nakano M, Hata K, Yatani H, Yoneda T. Zoledronic acid delays wound healing of the tooth extraction socket, inhibitsoral epithelial cell migration, and promotes proliferation and adhesion to hydroxyapatite of oral bacteria, without causing osteonecrosis of the jaw, in mice. J Bone Miner Metab. 2010;28:165-75. PMID: 19882100.

32. Bi Y, Gao Y, Ehirchiou D, Cao C, Kikuiri T, Le A, Shi S, Zhang L. Bisphosphonates cause osteonecrosis of the jaw-like disease in mice. Am J Pathol. 2010;177:280-90. PMID: 20472893.

33. Allen MR, Burr DB. Mandible matrix necrosis in beagle dogs after 3 years of daily oral bisphosphonate treatment. J Oral Maxillofac Surg. 2008;66:987-94. PMID: 18423290.

34. Allen MR, Kubek DJ, Burr DB. Cancer treatment dosing regimens of zoledronic acid result in near-complete suppression of mandible intracortical bone remodelling in beagle dogs. J Bone Miner Res. 2010;25:98-105. PMID: 19580463.

35. Huja SS, Mason A, Fenell CE, Mo X, Hueni S, D'Atri AM, Fernandez SA. Effects of shortterm zoledronic acid treatment on bone remodelling and healing at surgical sites in the maxilla and mandible of aged dogs. J Oral Maxillofac Surg. 2011;69:418-27. PMID: 21122971.

36. Huja SS, Kaya B, Mo X, D'Atri AM, Fernandez SA. Effect of zoledronic acid on bone healing subsequent to miniimplant insertion. Angle Orthod. 2011;81:363-9. PMID: 21261489.

37. Pautke C, Kreutzer K, Weitz J, Knödler M, Münzel D, Wexel G, Otto S, Hapfelmeier A, Stürzenbaum S, Tischer T. Bisphosphonate related osteonecrosis of the jaw: a minipig large animal model. Bone. 2012;51:592-9. PMID: 22575441.
38. Patel S, Choyee S, Uyanne J, Nguyen AL, Lee P, Sedghizadeh PP, Sedghizadeh PP, Kumar SK, Lytle J, Shi S, Le AD. Nonexposed bisphosphonate-related osteonecrosis of the jaw: a critical assessment of current definition, staging, and treatment guidelines. Oral Dis. 2012;18:625-32. PMID: 22420684.

39. Di Fede O, Fusco V, Matranga D, Solazzo L, Gabriele M, Gaeta GM, Favia G, Sprini D, Peluso F, Colella G, Vescovi P, Campisi G. Osteonecrosis of the jaws in patients assuming oral bisphosphonates for osteoporosis: a retrospective multi-hospital-based study of 87 Italian cases. Eur J Intern Med. 2013;24:784-90. PMID: 23768563.

40. Fedele S, Porter SR, D’Aiuto F, Aljohani S, Vescovi P, Manfredi M, Arduino PG, Broccoletti R, Musciotto A, Di Fede O, Lazarovici TS, Campisi G, Yarom N. Nonexposed variant of bisphosphonateassociated osteonecrosis of the jaw: a case series. Am J Med. 2010;123:1060-4. PMID: 20851366.

41. Rocha GC, Jaguar GC, Moreira CR, Neves EG, Fonseca FP, Pedreira EN. Radiographic evaluation of maxillofacial region in oncology patients treated with bisphosphonates. Oral Surg Oral Med Oral Pathol Oral Radiol. 2012;114:S19-25. PMID: 23083951.

42. Treister N, Sheehy N, Bae EH, Friedland B, Lerman M, Woo S. Dental panoramic radiographic evaluation in bisphosphonate associated osteonecrosis of the jaws. Oral Dis. 2009;15:88-92. PMID: 18992020.

\section{Acknowledgement}

Endodontics Department, Universidade de São Paulo (FOB/USP), for the use of MicroCT.

\section{Correspondence:}

Camila Lopes Cardoso

Rua Irmã Arminda 10-50

17011-160 Bauru - SP Brasil

Tel.:(55 14)99853-6050

cardoso_lopes@yahoo.com.br

Received: Jan 20, 2016

Review: Mar 21, 2016

Accepted: Apr 22, 2016

Conflict of interest: none

Financial source: FAPESP (process nº 2014/10693-6)

${ }^{1}$ Research performed at Oral Surgery Department, Universidade Sagrado Coração (USC), and Oral Surgery Department, Universidade de São Paulo (USP), Bauru-SP, Brasil. 